IZA DP No. 7955

Brain Drain, Educational Quality and Immigration Policy: Impact on Productive Human Capital in Source and Host Countries, with Canada as a Case Study

Maurice Schiff

February 2014 


\title{
Brain Drain, Educational Quality and Immigration Policy: Impact on Productive Human Capital in Source and Host Countries, with Canada as a Case Study
}

\author{
Maurice Schiff \\ World Bank and IZA
}

Discussion Paper No. 7955
February 2014

IZA

P.O. Box 7240

53072 Bonn

Germany

Phone: +49-228-3894-0

Fax: +49-228-3894-180

E-mail: iza@iza.org

Any opinions expressed here are those of the author(s) and not those of IZA. Research published in this series may include views on policy, but the institute itself takes no institutional policy positions. The IZA research network is committed to the IZA Guiding Principles of Research Integrity.

The Institute for the Study of Labor (IZA) in Bonn is a local and virtual international research center and a place of communication between science, politics and business. IZA is an independent nonprofit organization supported by Deutsche Post Foundation. The center is associated with the University of Bonn and offers a stimulating research environment through its international network, workshops and conferences, data service, project support, research visits and doctoral program. IZA engages in (i) original and internationally competitive research in all fields of labor economics, (ii) development of policy concepts, and (iii) dissemination of research results and concepts to the interested public.

IZA Discussion Papers often represent preliminary work and are circulated to encourage discussion. Citation of such a paper should account for its provisional character. A revised version may be available directly from the author. 


\section{ABSTRACT \\ Brain Drain, Educational Quality and Immigration Policy: Impact on Productive Human Capital in Source and Host Countries, with Canada as a Case Study*}

With the 1967 reform, Canada's immigration policy changed from a country-preference system to a points system. The latter provides points according to applicants' education level but abstracts from the quality of their education. This paper considers the points system, the country-preference system, as well as a system that includes both educational quantity and quality and is termed the " $q^{2}$ points system." It focuses on the policies' impact on immigrants' average productive human capital - the product of educational quality and quantity - or skill level, $S_{x}$ (for policy $x$ ). It shows, among others, that i) $S_{x}$ is greater under the $q^{2}$ system than under the points system $\left(S_{q}>S_{h}\right)$; ii) a switch from a points system to a $q^{2}$ system results in a human capital gain or net brain gain for Country 1 (the high-education quality country) and a loss or net brain drain for Country 2; iii) $S_{x}$ is greater under the country-preference system than under the points system $\left(S_{p}>S_{h}\right)$; iv) whether $S_{x}$ is greater under the $q^{2}$ or the countrypreference system is ambiguous, with $S_{q}>(<) S_{p}$ if the quality of education in Country 1 relative to Country 2 is higher (lower) than the degree of preference for migrants from Country 1 relative to Country 2; and v) an increase in education quality in the high- (low-) quality source country has a positive (ambiguous) impact on $S_{x}$ under all three policies and the impact is larger under the $q^{2}$ than under the points system.

JEL Classification: F22, 120

Keywords: points system, country-preference system, education quantity-quality system, Canadian immigration policy, human capital impact

Corresponding author:

Maurice Schiff

World Bank

1818 H Street NW

Washington, DC 20433

USA

E-mail: schiffmaurice@yahoo.com

\footnotetext{
*I would like to thank an anonymous referee for excellent comments and suggestions.
} 


\section{Introduction}

A number of studies have examined the impact of the brain drain on human capital in migrants' source countries. The issue has been investigated both theoretically (e.g., Mountford 1997, Docquier et al. 2011) and empirically (e.g., Beine et al. 2004, 2008). Studies in a recent volume by Boeri et al. (2012) also focus on brain drain and brain gain, and Commander et al. (2004) provide an early survey of the costs and benefits of the brain drain, covering both these and other brain-drain-related issues.

This paper contributes to the literature by i) examining the impact of various immigration policies on productive human capital, also referred to in this paper as the skill level, which is a function of both the quality and quantity (or level) of education or human capital; ii) doing so for both source and destination countries; and iii) comparing migrants' average skill levels under the various immigration regimes and determining the preferred regime from source and destination countries’ viewpoint. ${ }^{1}$

The immigration regimes examined in this paper are the points system, the "countrypreference" system and the " $q^{2}$ system." Under the points system, applicants must obtain a minimum number of points to be eligible for an immigrant visa, with the points depending in part on applicants' education level. Destination countries using the points system include Australia, Canada, Denmark, Hong Kong, New Zealand, Singapore and the UK. Hinte, Rinne and Zimmermann (2011) have proposed such a system for Germany.

The analysis provided here is conducted with Canada's immigration policy in mind, though it applies to other destination countries as well. The points system specifies a number of characteristics that enter in the calculation of the number of points obtained by prospective migrants. The characteristics and the maximum number of points associated with them under Canada's points system are provided in Table 1.

The maximum number of points obtainable under the points system is 100, with 67 points needed to pass. This number was reduced from 75 points on September 18, 2003. This is

\footnotetext{
${ }^{1}$ The selection of the average level of education as a criterion for evaluating the various immigration regimes is motivated by endogenous growth theory (Lucas 1988) where economic growth is an increasing function of the average stock of human capital.
} 
expected to result in a considerable increase in the number of applicants who meet Canada's visa requirement. And the maximum number of points for several of the characteristics listed in Table 1 was changed as well, with a reduction from 21 to 15 points for experience, and an increase from 24 to 28 points for English and/or French skills, and from 10 to 12 points for age (with the maximum obtained for age between 21 and 49 points, declining symmetrically for younger and older applicants, and reaching zero for those 16 and under or 54 and over). The number of points for education, arranged employment in Canada and for adaptability was kept unchanged. The change in the relative importance of the various criteria was made in the hope of improving the match between the supply and demand for migrants' skills.

\section{Table 1: Characteristics and Maximum Points under Canada's Points System}

\section{$\underline{\text { Characteristics }}$}

English and/or French Skills

Education

Experience

Age

Arranged Employment in Canada

Adaptability

Total

\section{Maximum Number of Points}

28

25

15

12

10

10

It can be argued that under heterogeneity, the level of education may not be independent of the other characteristics and individuals might self-select into migration. For instance, prospective migrants from English or French-speaking countries would obtain 28 points, which should raise the incentive to acquire education, given that it would be extremely difficult for someone who knew neither of these languages to obtain the required 67 points. For instance, if such an applicant had gotten zero points for 'adaptability,' the maximum number of points s/he would have been able to attain would have been 62, so that even a PhD or Master's degree with at least 17 years of full-time education - the requirement for obtaining the maximum number of points for education - would have been of no help.

However, given the focus of the paper on immigration policies with different education criteria and on their impact on migrants' average level of productive human capital (a 
combination of educational quantity and quality), and for the sake of simplicity and clarity, it is assumed that the additional characteristics are orthogonal to countries' educational quality. This enables the analysis to focus on the impact of these policies' different educational criteria on migrants' average productive human capital. Note, though, that the cross-country heterogeneity in educational quality implies that migrants do self-select according to quality. As is shown in Sections 2 to 6, this feature is fundamental for the comparison of the impact of the various immigration policies. Note Analysis of the impact of migrants' self-selection according to some of the other criteria is on my research agenda.

Though Canada's points system does not explicitly mention the quality of education as one of the characteristics for which points can be obtained, it might nevertheless play some role in the selection process. The fact is that Canada has signed bilateral agreements for the mutual recognition of educational degrees with a number of countries (e.g., with France), and educational quality was clearly an important criterion in the selection of the countries with which such agreements were signed. Insofar as this selection criterion is reflected in the points obtained under the points system, the difference in the impact of the points and $q^{2}$ systems obtained in this paper provides an upper bound of the actual difference in the impact of the two immigration policies.

Under the country-preference system, a destination country provides preferential access to individuals from specific countries. Such a system was more common in the past in Canada and the US. In the case of Canada, early immigrants consisted mostly of Englishand French-speaking Europeans, and later from the rest of Europe. ${ }^{2}$

The $q^{2}$ system is similar to the points system except for the fact that points are obtained for both education quantity and quality - hence the name " $q^{2}$ system". Such a system is used in the US (H1-B visa), Germany under the German Immigration Act, and in Norway, Spain and Sweden.

\footnotetext{
${ }^{2}$ While the points system was seen as a move away from the exclusive nature of the country-preference policy, Clifton (2010) has argued that the policy is anti-low-skill migrants, with skilled migrants granted pathways to permanent entry and low-skilled ones restricted to temporary and more precarious legal status, resulting in reduced access to key social, economic and civic rights relative to the former.
} 
The points and $q^{2}$ systems also require individuals to have a minimum or threshold level of education which is larger under the US and German vetting systems (Bachelor's degree) than under the points systems of Australia (two years of university study) and Canada (high-school degree). Appendix 1 presents some of the main aspects of two immigration regimes, Canada's points system and the US H1-B visa.

The overwhelming majority of Canada's early immigration came from the UK, Ireland and France, with the Province of Quebec being the latter's main destination, followed in the $20^{\text {th }}$ century by immigrants from continental Europe. Since the 1970s, most immigration has originated in developing countries. The change in the composition of source countries is essentially due to the 1967 revision of Canada's Immigration Act, which established a points system as Canada's official immigration policy, a policy that continues to this day. Asia has been the most important developing source region in recent years, with over a third of all immigrants in 2010 coming from three Asian countries, the Philippines (13\%), India (10.8\%) and China (10.8\%).

Canada's points system has been questioned in recent years as immigrants' integration into the labor market has become increasingly difficult, with their income relative to that of the native population steadily deteriorating over the past twenty five years. While incomes of immigrants with 10 years of residence in the decades before 2000 were equal to the national average, by 2000 they only amounted to $80 \%$ of the national average. Moreover, as shown by a 2003 study by Statistics Canada, the low-income rate among recent immigrants, which was 1.4 times that of natives in 1980, had increased to 2.5 times by 2000, with the deterioration affecting most types of immigrants; and a 2007 update of the study showed the figure had increased to 3.2 times by 2004 . Note that this occurred despite immigrants having a higher share of individuals with Ph.D. and Master's degrees than natives.

Immigrants have also experienced a sharp increase in unemployment rates. In a 2007 study, Statistics Canada showed an overall unemployment rate in 2006 of 11.5\% for recent immigrants (or over 2.3 times the $4.9 \%$ rate for natives) and a $7.3 \%$ average rate for immigrants in the country between 5 and 10 years (or 50\% above the native rate). Moreover, the amount of time since arrival until immigrants' unemployment rate 
converged to that of natives doubled from 5 to 10 years between 1981 and 2001. And an earlier study (Statistics Canada, 2001) found the skilled migrants' unemployment rate to be $34 \%$ to be significantly higher than the immigrant average.

The deterioration of immigrants' economic conditions relative to that of natives has led both analysts and policy-makers to consider the possibility of a reform of the points system. It motivated, for instance, the various studies by McHale and Rogers (e.g., McHale and Rogers, 2009) who view the lack of accounting for migrants' quality of education as contributing to the deterioration of migrants' labor market situation relative to that of Canada's natives. It also motivated the study by Aydemir (2011) who studies the efficacy of immigrant selection based on skill requirements in the Canadian context. He shows that though migration under the points system results in a higher education level than under family preferences, difficulties in the transfer of foreign human capital imply that immigrants with a higher level of education do not necessarily perform better in the labor market. He also finds that the other characteristics used to assess admissibility have very limited power to predict labor market success.

Coulombes et al. (2012) use a proxy for country-specific quality of migrants' human capital and find that migrants' lower quality relative to Canada's natives completely negates the quantitative advantage in human capital they possess. They conclude that the quality factor is key to understanding the wage gap between migrants and Canadian natives. As for employment, Phythian and Anisef (2009) estimate employment probability by running logit regressions using data from the Longitudinal Survey of immigrants to Canada. They find little difference in the employment rates of skilled workers and family immigrants despite the former's substantially higher education level. And Green and Green (1995) “ ... find that entry class and source country composition of inflow have impacts that have swamped the effects of the point system in the last two decades” (my italics).

Furthermore, Jason Kenney, Canada's Immigration Minister (until July 2013), who oversaw the recent reform - that places greater emphasis on fluency in English and French and on age, and reduced emphasis on work experience - stated in a March 2013 
interview as part of his explanation for the reform: "I don't think we can take for granted our relative success in integration” (Wall Street Journal, August 31, 2013).

Given the worsening labor-market outcomes for immigrants under the points system and the fact that a return to a country-preference immigration policy is not possible, the question arises as to what Canada can do to attract a larger share of immigrants who are likely to do better in the job market. ${ }^{3}$ The paper examines the impact of three immigration policies on immigrants' productive human capital, defined as the expected return on human capital in Canada's labor market, which depends on both the quantity and quality of immigrants' education. The objective is to assess the impact on immigrants' average productive human capital of a change in immigration policy from the pre-1967 country-preference system to the current points system, and from the points system to $q^{2}$ system.

The remainder of the paper is organized as follows. Section 2 presents the model. Section 3 examines the points system, Section 4 the country-preference system - with an analysis of employers' discrimination in Sub-section 4.1. Section 5 examines the vetting system, Section 6 compares the impact of the various policies and Section 7 concludes.

\section{Model}

Assume two source countries $j(j=1,2)$ whose exogenously given quality of education is $q_{j}$, with $q_{1}>q_{2}$. Thus, Country 1 (2) might be a high (middle or low) income country or, alternatively, a middle (low) income country. The population of both countries consists of homogeneous, risk-neutral individuals $l$ and is of size 1 , i.e., $l \in[0,1]$. Individual income for Country $j$ 's natives residing in the country of origin (destination) is denoted by $y_{0 j}$ $\left(y_{\mathrm{d} j}\right)$, with:

$$
\begin{aligned}
& y_{0 j}=\alpha_{0} q_{j} h_{j}=\alpha_{0} s_{j}, h_{j} \in[0,1], \\
& y_{\mathrm{d} j}=\alpha_{\mathrm{d}} q_{j} h_{j}=\alpha_{\mathrm{d}} s_{j}, 0<\alpha_{0}<\alpha_{\mathrm{d}}<1,
\end{aligned}
$$

\footnotetext{
${ }^{3}$ The recent reform appears to be marginal at best and it is doubtful that it will have a significant impact on migrants' labor market performance.
} 
where $s_{j} \equiv q_{j} h_{j}$ is the productive human capital or skill level available to individuals from Country $j$, defined as the product of the quality of human capital $q_{j}$ and its quantity or level $h_{j}$.

Denoting the immigration probability for individuals from Country $j$ by $p_{j}$, their expected income $y_{j}$ is:

$y_{j}=\left(1-p_{j}\right) y_{0 j}+p_{j} y_{\mathrm{d} j} ; p_{j} \in[0,1] .^{4}$

Individual utility in Country $j$ is $U\left(e_{j}\right)$, where $e_{j}$ denotes consumption expenditures and is equal to the difference between expected income, $y_{j}$, and the cost of education $c\left(h_{j}\right)=$ $\frac{h_{j}^{2}}{2}$. Given risk-neutrality, utility is linear in $e_{j}$. For simplicity and without affecting any of the solutions, we posit $U\left(e_{j}\right)=e_{j}$. Then:

$U\left(e_{j}\right)=e_{j}=y_{j}-\frac{h_{j}^{2}}{2}=\left(1-p_{j}\right) \alpha_{0} s_{j}+p_{i} \alpha_{\mathrm{d}} s_{j}-\frac{h_{j}^{2}}{2}=\left[\alpha_{0}+p_{j}\left(\alpha_{\mathrm{d}}-\alpha_{0}\right)\right] s_{j}-\frac{h_{j}^{2}}{2}$.

Individuals in $j$ select an education level $h_{j}$ that maximizes their utility, taking education quality $q_{j}$ and immigration policy as given. ${ }^{5}$ Interior solutions are assumed throughout.

\section{Points System}

Under the points system, the immigration probability depends on an applicant's quantity of human capital. Hence, we use a subscript $h$ to denote the variables in this case.

Assume the immigration probability function takes the form:

\footnotetext{
${ }^{4}$ Canada's points system requires a high-school degree as a minimum education level, $\mathrm{h}_{\mathrm{M}}$. As shown in Appendix 2, this discontinuity implies that a critical level of education, $\mathrm{h}_{0}<\mathrm{h}_{\mathrm{M}}$, exists and if the optimal education level, $h^{*}$, in the continuous case is such that $h^{*}<h_{0}$, then a policy with a minimum level of education $\mathrm{h}_{\mathrm{M}}$ has no impact on $\mathrm{h}^{*}$ and nobody migrates. If $\mathrm{h}_{0}<\mathrm{h}^{*}<\mathrm{h}_{\mathrm{M}}$, then source country's individuals raise their education level $h=h^{*}$ to $h=h_{M}$ and migration is possible. And if $h_{0}<h_{M}<h^{*}$, then the minimum level of education has no impact. Appendix 2 solves for $h_{0}$. Countries where $h^{*}<h_{0}$ are ignored as the analysis deals with the impact of the policy on migrants' education while countries where $\mathrm{h}_{0}<\mathrm{h}^{*}<\mathrm{h}_{\mathrm{M}}$ do not respond to changes in education quality. The model therefore assumes $h^{*}>h_{M}$.

${ }^{5}$ Individuals are assumed to bear the full cost of their education, i.e., source country governments do not subsidize education. The model should be amended if they do and if education policy is endogenous and affected by destination countries’ immigration policies (e.g., as in Docquier et al., 2011).
} 
$p_{j h}=\pi h_{j h}, \pi>0$

Since $p_{i}, h_{i} \in(0,1]$, it follows that $\pi \in(0,1]$. From (3) and (4), we have:

$e_{j h}=\left(1-\pi h_{j h}\right) \alpha_{0} s_{j h}+\pi h_{j h} \alpha_{\mathrm{d}} s_{j h}-\frac{h_{j h}^{2}}{2}=\left[\alpha_{0}+\pi h_{j h}\left(\alpha_{\mathrm{d}}-\alpha_{0}\right)\right] q_{j} h_{j h}-\frac{h_{j h}^{2}}{2}$.

Maximizing $e_{j h}$, the solution for $h_{j h}$ is:

$h_{j h}=\frac{\alpha_{0} q_{j}}{1-2 \pi q_{j}\left(\alpha_{\mathrm{d}}-\alpha_{0}\right)} \equiv \frac{\alpha_{0} q_{j}}{\varphi_{j h}}, \varphi_{j h}=1-2 \pi q_{j}\left(\alpha_{\mathrm{d}}-\alpha_{0}\right) ; q_{1}>q_{2} \Leftrightarrow h_{1 h}>h_{2 h}$,

$\frac{\partial h_{j h}}{\partial q_{j}}=\frac{\alpha_{0}}{\varphi_{j h}^{2}}>0, \frac{\partial^{2} h_{j h}}{\partial q_{j}^{2}}=\frac{4 \pi \alpha_{0}\left(\alpha_{\mathrm{d}}-\alpha_{0}\right)}{\varphi_{j h}^{3}}>0$.

We assume an interior solution $h_{j h}>0$, i.e., $\varphi_{j h}>0$ (which, from the second-order condition, ensures that $h_{j h}$ maximizes $e_{j h}$ ). Not surprisingly, $h_{1 h}>h_{2 h}$, i.e., the level of human capital increases with educational quality. As shown in equation (6), $h_{j h}$ increases at an increasing rate with $q_{j}{ }^{6}$

Since population size is 1 , it follows that the number of immigrants from Country $j$ is $m_{j h}=p_{j h}=\pi h_{j h}$ and their share in the total number of immigrants (or ratio), $r_{j h}$, is:

$r_{j h}=\frac{m_{j h}}{m_{1 h}+m_{2 h}}=\frac{h_{j h}}{h_{1 h}+h_{2 h}}=\frac{q_{j} \varphi_{(3-j) h}}{q_{1} \varphi_{2 h}+q_{2} \varphi_{1 h}}, r_{1 h}>r_{2 h}=1-r_{1 h} \Leftrightarrow r_{2 h}<\frac{1}{2}<r_{1 h}$,

with $3-j=1$ (2) when $j=2$ (1).

The immigrant average skill level, $S_{h}$, is:

$S_{h}=r_{1 h} s_{1 h}+r_{2 h} s_{2 h}=\frac{q_{1} h_{1 h}^{2}+q_{2} h_{2 h}^{2}}{h_{1 h}+h_{2 h}}$.
$\frac{\partial S_{h}}{\partial q_{j}}=r_{j h} \frac{\partial s_{j h}}{\partial q_{j}}+\left(s_{j h}-s_{(3-j) h}\right) \frac{\partial r_{j h}}{\partial q_{j}} ; \frac{\partial r_{j h}}{\partial q_{j}}>0, \frac{\partial s_{j h}}{\partial q_{j}}>0$,

\footnotetext{
${ }^{6}$ Moreover, $h_{j h}>\alpha_{0} q_{j}$, i.e., human capital is greater under the points system than under autarky (no migration), the reason being that $\alpha_{\mathrm{d}}>\alpha_{0}$.
} 
Since $q_{1}>q_{2}$, it follows that $s_{1 h}>s_{2 h}$ and, with $\frac{\partial s_{j h}}{\partial q_{j}}>0$ and $\frac{\partial r_{j h}}{\partial q_{j}}>0$, it implies that $\frac{\partial S_{h}}{\partial q_{1}}>0$. On the other hand, $\frac{\partial S_{h}}{\partial q_{2}} \gtreqless 0$ because its first term is positive while its second term is negative (since $s_{2 h}-s_{1 h}<0$ ).

This makes perfect sense: an increase in $q_{1}$ raises $h_{1 h}$ and thus raises $s_{1 h}=q_{1} h_{1 h}$ as well as $r_{1 h}$. This results in an increase in $S_{h}$. On the other hand, though the increase in $q_{2}$ has a positive impact on $r_{2 h}$ and on $S_{h}$, the increase in $r_{2 h}$ means that $r_{1 h}=1-r_{2 h}$ declines, i.e., the increase in $q_{2}$ results in a decrease in the share of immigrants from Country 1 who have the highest quality and quantity of education and thus the highest skill level $s_{1 h}$. This results in a decrease in $S_{h}$ that depends on the difference in skill levels between Country 1 and Country 2's immigrants and on the impact of the increase in $q_{2}$ on Country 2's share of all immigrants, $r_{2 h}$. The net impact is thus ambiguous. The same ambiguity obtains with a discrete change in education quality, for instance if $q_{2}$ in Country 2 increases to $q_{3}<q_{1}\left(S_{h}\right.$ increases if $\left.q_{3} \geq q_{1}\right)$.

The results are collected in Proposition 1 below.

Proposition 1: Assume a destination country whose immigration policy consists of a points system and whose immigrants come from two source countries 1 and 2 with education quality $q_{1}>q_{2}$, and define the skill level (or productive human capital) as the product of the quantity and quality of education. Then: i) a marginal or discrete increase in $q_{1}$ has a positive impact on immigrants' average skill level $S_{h}$, ii) a marginal increase in $q_{2}$ has an ambiguous impact on $S_{h}$, and a discrete increase from $q_{2}$ to, say, $q_{3}$, has an ambiguous impact on $S_{h}$ if $q_{2}<q_{3}<q_{1}$ and a positive impact if $q_{3} \geq q_{1}$.

\subsection{Discrimination by Employers}

Host country employers may discriminate against immigrants and typically more so against those who differ more (ethnically, culturally or otherwise) from host country natives. This situation seems to prevail in many if not all destination countries, including Canada. One of the classifications of Canada's minorities refers to visible and non-visible minorities, and discrimination is more likely to occur against the former. This situation may be represented by a lower wage rate, implying a lower expected return on education and thus resulting in a lower level of education. This can be seen from equation (6) where $\alpha_{d}$ is replaced by $\alpha$, where $\alpha_{0}<\alpha<\alpha_{d}$. 
What is the impact of discrimination on $S_{h}$ ? That depends. The reduction in human capital has a negative impact on $S_{h}$. It also has a negative impact on the share of individuals who are affected by discrimination. Thus, if discrimination is against immigrants from Country 2, the fact that their share falls has a positive impact on $S_{h}$ so that the overall impact on immigrants' average skill level $S_{h}$ is ambiguous. On the other hand, discrimination against individuals from Country 1 reduces the level of $S_{h}$. In the case where discrimination affects all immigrants equally, the impact on $S_{h}$ is negative as well. Thus, we have:

Proposition 2: Employer discrimination against immigrants that lowers their wage rate results in i) a lower average skill level, $S_{h}$, for immigrants if discrimination is against immigrants from Country 1 whose education quality is high; ii) a lower $S_{h}$ level if discrimination is against all immigrants, though not as low as in Case i) above; and iii) the impact on $S_{h}$ is ambiguous if discrimination is against Country 2's immigrants and may in fact be positive.

\section{Country-Preference System}

Before the 1967 revision of its Immigration Act, Canada’s immigration policy consisted in providing preferential access to European individuals, a region with a high quality of education and which is referred to here as Country 1 . The purpose of the analysis in this section is to determine immigrants' average skill level under this policy and compare it with the level under the points system. Hence, we want to keep the average immigration probability at any level of human capital unchanged in order to isolate the impact of a relative change in country preference.

Denoting the parameter of the immigration probability function by $\pi_{1}$ for Country 1 and $\pi_{2}$ for Country $2\left(\pi_{1}>\pi_{2}>0\right)$, we have $\pi=\frac{1}{2}\left(\pi_{1}+\pi_{2}\right)$, i.e., the average immigration probability at any level of human capital under the country-preference system is equal to the immigration probability under the points system. Then, one can write $\pi_{1}=\pi(1+\gamma)$, and $\pi_{2}=\pi(1-\gamma)$. Thus, equations (4) and (6) are replaced by:

$$
\begin{aligned}
& p_{1 p}=\pi_{1} h_{1 p}=\pi(1+\gamma) h_{1 p}, p_{2 p}=\pi_{2} h_{2 p}=\pi(1-\gamma) h_{2 p}, \\
& h_{1 p}=\frac{\alpha_{0} q_{1}}{1-2 \pi(1+\gamma) q_{1}\left(\alpha_{\mathrm{d}}-\alpha_{0}\right)}=\frac{\alpha_{0} q_{1}}{\varphi_{1 p}}>h_{2 p}=\frac{\alpha_{0} q_{2}}{1-2 \pi(1-\gamma) q_{2}\left(\alpha_{\mathrm{d}}-\alpha_{0}\right)}=\frac{\alpha_{0} q_{2}}{\varphi_{2 p}},
\end{aligned}
$$


with $h_{1 p}>h_{2 p}$ because $q_{1}>q_{2}$ and $\pi_{1}>\pi_{2}$.

From (11), we have:

$$
\begin{aligned}
\frac{\partial h_{1 p}}{\partial \gamma} & =\frac{2 \pi \alpha_{0}\left(\alpha_{\mathrm{d}}-\alpha_{0}\right) q_{1}^{2}}{\varphi_{1 p}^{2}}>0, \frac{\partial h_{2 p}}{\partial \gamma}=-\frac{2 \pi \alpha_{0}\left(\alpha_{\mathrm{d}}-\alpha_{0}\right) q_{2}^{2}}{\varphi_{2 p}^{2}}<0, \frac{\partial h_{1 p}}{\partial \gamma}+\frac{\partial h_{2 p}}{\partial \gamma}>0, \\
\frac{\partial^{2} h_{j p}}{\partial \gamma^{2}} & =\frac{4 \pi^{2} \alpha_{0}\left(\alpha_{\mathrm{d}}-\alpha_{0}\right)^{2} q_{j}^{3}}{\varphi_{j p}^{3}}>0, j=1,2 .
\end{aligned}
$$

Thus, an increase in $\gamma$ - i.e., an increase in $\pi_{1}$ and decrease in $\pi_{2}$ that keeps the average immigration probability $p_{j p}$ at any human capital level $h_{j p}$ unchanged - has a positive impact on immigrants' average human capital. In other words, the increase in the level of human capital of Country 1's immigrants is greater than the decrease in that of Country 2's immigrants. This is due to the fact that, as shown in (12), $h_{j p}$ is convex in $\gamma$.

Since $S_{p}=r_{1 p} S_{1 p}+r_{2 p} S_{2 p}$, we have:

$\frac{\partial s_{p}}{\partial \gamma}=r_{1 p} \frac{\partial s_{1 p}}{\partial \gamma}+r_{2 p} \frac{\partial s_{2 p}}{\partial \gamma}+\left(s_{1 p}-s_{2 p}\right) \frac{\partial r_{1 p}}{\partial \gamma}$

Since $\frac{\partial h_{1 p}}{\partial \gamma}+\frac{\partial h_{2 p}}{\partial \gamma}>0$ and $q_{1}>q_{2}$, it follows that $\frac{\partial s_{1 p}}{\partial \gamma}+\frac{\partial s_{2 p}}{\partial \gamma}>0$. Hence, $r_{1 p}>r_{2 p}$ implies $r_{1 p} \frac{\partial s_{1 p}}{\partial \gamma}+r_{2 p} \frac{\partial s_{2 p}}{\partial \gamma}>0$, and since $s_{1 p}>s_{2 p}$ and $\frac{\partial r_{1 p}}{\partial \gamma}>0$, it follows that $\frac{\partial s_{p}}{\partial \gamma}>$ 0 . Thus, as expected, giving preferential access to immigrants from the country with the higher education quality raises immigrants average skill level, i.e.:

$\gamma>0 \Leftrightarrow S_{p}>S_{h}, \frac{\partial\left(S_{p}-S_{h}\right)}{\partial \gamma}>0$

Immigration to Canada under its pre-1967 policy was restricted to European individuals. In that case, $\gamma=1$, or $\pi_{1}=2 \pi$ and $\pi_{2}=0$. Then, immigrants' average level of education is at a maximum and is equal to $h_{1 p}=\frac{\alpha_{0} q_{1}}{1-4 \pi q_{1}\left(\alpha_{\mathrm{d}}-\alpha_{0}\right)}$. Given that $r_{1 p}=1$, $S_{p}=S_{1 p}$ is also maximized and is equal to $S_{p}^{\max }=\frac{\alpha_{0} q_{1}^{2}}{1-4 \pi q_{1}\left(\alpha_{\mathrm{d}}-\alpha_{0}\right)}>S_{h}$. 
As shown in (14), a switch from a country-preference to a points system leads to a decline in immigrants' average skill level and worsening of their economic condition and integration into Canada's economy. Because of its discriminatory nature, the countrypreference system is unlikely to be an acceptable option for an advanced liberal democracy that is considering a reform in its immigration policy. ${ }^{7}$ On the other hand, pressure has been growing to improve immigrants' economic integration. We turn now to an alternative immigration policy, the $q^{2}$ system, which may help resolve or at least ameliorate this problem by taking both the quantity and quality of education into account.

\section{The $q^{2}$ System}

Under the $q^{2}$ system, the host country's government cares about immigrants' productive human capital or skill level. Hence, the immigration probability is given by:

$p_{j v}=\pi q_{j} h_{j q}$

Maximizing (3) subject to (14), we have:

$$
\begin{aligned}
& h_{j q}=\frac{\alpha_{0} q_{j}}{1-2 \pi q_{j}^{2}\left(\alpha_{\mathrm{d}}-\alpha_{0}\right)}=\frac{\alpha_{0} q_{j}}{\varphi_{j q}}, \varphi_{j q} \equiv 1-2 \pi q_{j}^{2}\left(\alpha_{\mathrm{d}}-\alpha_{0}\right) ; q_{1}>q_{2} \Leftrightarrow h_{1 q}>h_{2 q} ; \\
& \frac{\partial h_{j q}}{\partial q_{j}}=\frac{\alpha_{0}\left[1+2 \pi q_{j}^{2}\left(\alpha_{d}-\alpha_{0}\right)\right]}{\varphi_{j q}^{2}}>0, \frac{\partial^{2} h_{j q}}{\partial q_{j}^{2}}=\frac{4 \pi \alpha_{0}\left(\alpha_{\mathrm{d}}-\alpha_{0}\right)\left[3+2 \pi q_{j}^{2}\left(\alpha_{d}-\alpha_{0}\right)\right]}{\varphi_{j q}^{3}}>0 .
\end{aligned}
$$

Note from (11) and (14) that the only difference between $h_{j q}$ and $h_{j h}$ is that $q_{j}$ appears in quadratic form in the denominator of $h_{j q}$ and in linear form in $h_{j h}$. The solution for the skill level, migrant share and immigrants’ average skill level is:

$s_{j q}=q_{j} h_{j q}=\frac{\alpha_{0} q_{j}^{2}}{\varphi_{j q}}, r_{j q}=\frac{q_{j} h_{j q}}{q_{j} h_{j q}+q_{j} h_{j q}}$

$S_{q}=r_{1 q} s_{1 q}+r_{2 q} S_{2 q}=\frac{\left(q_{1} h_{1 q}\right)^{2}+\left(q_{2} h_{2 q}\right)^{2}}{q_{1} h_{1 q}+q_{2} h_{2 q}}$

Proposition 3. Results under the $q^{2}$ system are similar to those under the points system, though with a few differences, i.e.: i) a marginal or discrete increase in $q_{1}$ has a positive

\footnotetext{
${ }^{7}$ It is of course acceptable for a EU country to give preferential (free) access to immigrants from other EU countries, which is in fact the case.
} 
impact on immigrants' average skill level $S_{q}$ that is larger than the positive impact on $S_{h}$; ii) a marginal increase in $q_{2}$ has an ambiguous impact on $S_{q}$; iii) a discrete increase from $q_{2}$ to, say, $q_{3}$, has an ambiguous impact on $S_{q}$ if $q_{2}<q_{3}<q_{1}$ and has a positive impact if $q_{3} \geq q_{1}$, and these impacts are larger for $S_{q}$ than for $S_{h}$; iv) the latter implies that the increase from $q_{2}$ to $q_{3}$ is more likely to have a positive impact on $S_{q}$ than on $S_{h}$, i.e., the range of $q_{3}$-values for which the impact on immigrants' average skill level is negative is smaller under the $q^{2}$ system than under the points system.

\section{Comparing the Immigration Policies}

In this section, we compare the three immigration policies. Section 6.1 compares the points and $q^{2}$ systems and Section 6.2 compares the $q^{2}$ and country-preference systems.

\subsection{Points vs. $q^{2}$ System}

For any level of human capital $h_{j}$, the immigration probability under the points system is $\pi h_{j}$ while the average probability under the $q^{2}$ system is $\pi h_{j}\left(\frac{q_{1}+q_{2}}{2}\right)$. To keep the average immigration probability unchanged when comparing the points and vetting systems, assume $\frac{q_{1}+q_{2}}{2}=1$. Then, one can write $q_{1}=1+\beta$ and $q_{2}=1-\beta$, with $\beta=$ $q_{1} 1=\frac{1}{2}\left(q_{1}-q_{2}\right)$. Thus, $p_{1 q}=\pi_{1} h_{1 q}=\pi(1+\beta) h_{1 q}, p_{2 q}=\pi_{2} h_{2 q}=\pi(1-\beta) h_{2 q}$, and we have:

$h_{1 q}=\frac{\alpha_{0}(1+\beta)}{1-2 \pi(1+\beta)^{2}\left(\alpha_{\mathrm{d}}-\alpha_{0}\right)}=\frac{\alpha_{0}(1+\beta)}{\varphi_{1 q}}, h_{2 q}=\frac{\alpha_{0}(1-\beta)}{1-2 \pi(1-\beta)^{2}\left(\alpha_{\mathrm{d}}-\alpha_{0}\right)}=\frac{\alpha_{0}(1-\beta)}{\varphi_{2 q}}$,

and from (6), we have:

$h_{1 h}=\frac{\alpha_{0}(1+\beta)}{1-2 \pi(1+\beta)\left(\alpha_{\mathrm{d}}-\alpha_{0}\right)}=\frac{\alpha_{0}(1+\beta)}{\varphi_{1 h}}, h_{2 h}=\frac{\alpha_{0}(1-\beta)}{1-2 \pi(1-\beta)\left(\alpha_{\mathrm{d}}-\alpha_{0}\right)}=\frac{\alpha_{0}(1-\beta)}{\varphi_{2 h}}$.

The only difference between the solutions for human capital in (16a) and (16b) is that the quality of education in the denominator is squared under the $q^{2}$ system (16a) and linear under the points system (16b). Consequently, we have:

$$
\begin{aligned}
& \varphi_{1 q}<\varphi_{1 h} \Rightarrow h_{1 q}>h_{1 h} \Rightarrow s_{1 q}=(1+\beta) h_{1 q}>s_{1 h}=(1+\beta) h_{1 h} ; \\
& \varphi_{2 q}>\varphi_{2 h} \Rightarrow h_{2 q}<h_{2 h} \Rightarrow s_{2 q}=(1-\beta) h_{2 q}<s_{2 h}=(1-\beta) h_{2 h} .
\end{aligned}
$$


We show below that the simple average of both the human capital level and the skill level is higher under the $q^{2}$ system than under the points system, and then show that the same holds for immigrants' (weighted) average skill level $\left(S_{q}>S_{h}\right)$, i.e., we show that:

$$
\begin{aligned}
& Z_{h} \equiv\left(h_{1 q}+h_{2 q}\right)-\left(h_{1 h}+h_{2 h}\right)=2 \pi \beta \alpha_{0}\left(\alpha_{d}-\alpha_{0}\right)\left[\frac{(1+\beta)^{2}}{\varphi_{1 q} \varphi_{1 h}}-\frac{(1-\beta)^{2}}{\varphi_{2 q} \varphi_{2 h}}\right]>0, \\
& Z_{s} \equiv\left(s_{1 q}+s_{2 q}\right)-\left(s_{1 h}+s_{2 h}\right)=2 \pi \beta \alpha_{0}\left(\alpha_{d}-\alpha_{0}\right)\left[\frac{(1+\beta)^{3}}{\varphi_{1 q} \varphi_{1 h}}-\frac{(1-\beta)^{3}}{\varphi_{2 q} \varphi_{2 h}}\right]>0, \\
& S_{q}=r_{1 q} s_{1 q}+r_{2 q} s_{2 q}>S_{h}=r_{1 h} s_{1 h}+r_{2 h} s_{2 h} .
\end{aligned}
$$

Since $\varphi_{1 q}<\varphi_{2 q}$ and $\varphi_{1 h}<\varphi_{2 h}$, it follows that $\varphi_{1 q} \varphi_{1 h}<\varphi_{2 q} \varphi_{2 h}$, which is a sufficient condition for $Z_{h}>0$ and $Z_{s}>0$, i.e., the simple average human capital and skill levels are higher under the $q^{2}$ than under the points system. Since $h_{1 q}>h_{1 h}$, it follows that $s_{1 q}>s_{1 h}$ and $p_{1 q}>p_{1 h}$. Thus, $r_{1 q}>r_{1 h}$, i.e., the skill level and the share of immigrants from the country where education quality is high (low) are both higher (lower) under the $q^{2}$ than under the points system. It follows therefore that $S_{q}>S_{h}$, which is not an unexpected outcome.

It is easily shown that $h_{1 q}, h_{1 h}, h_{1 q}-h_{1 h}, S_{q}, S_{h}, S_{q}-S_{h}$ and $S_{q} / S_{h}$ increase with parameters $\pi, \alpha_{0},\left(\alpha_{d}-\alpha_{0}\right)$ and $\beta$.

Thus, we have:

Proposition 3: A switch from a points system to a $q^{2}$ system results in i) a higher average skill level for destination country's immigrants; ii) a higher level of human capital in Country 1; and iii) a lower level of human capital in Country $2^{8}$

\subsection{The $q^{2}$ vs. Country-preference System}

\footnotetext{
${ }^{8}$ Note that the gain for Country 1 and loss for Country 2 are both ex-ante, i.e., they are expected changes before individuals find out whether or not they are selected as migrants. And though their choice is optimal in an ex-ante sense, ex post all those in Country 1 who are not selected lose in the sense that, given the fact that they were not selected, they would have been better off if they had not have increased their investment in education. Those in Country 2 who are not selected unambiguously benefit in an ex-post sense from their smaller investment in education. This holds unambiguously in the absence of positive externalities from education, though not necessarily under positive externalities.
} 
The level of human capital under the country-preference system is given by equation (11). With the quality of education $q_{1}=1+\beta$ and $q_{2}=1-\beta$, we have:

$h_{1 p}=\frac{\alpha_{0}(1+\beta)}{1-2 \pi(1+\gamma)(1+\beta)\left(\alpha_{\mathrm{d}}-\alpha_{0}\right)}, h_{2 p}=\frac{\alpha_{0}(1-\beta)}{1-2 \pi(1-\gamma)(1-\beta)\left(\alpha_{\mathrm{d}}-\alpha_{0}\right)}$.

Comparing (19) with (16a), it is clear that $\beta \gtreqless \gamma \Leftrightarrow h_{1 q} \gtreqless h_{1 p} \Leftrightarrow S_{q} \gtreqless S_{p}$. This holds

even though $h_{2 q} \lesseqgtr h_{2 p}$, because differences in human capital between the two systems are larger for Country 1 than for Country 2 (in absolute value).

Thus, we have:

Proposition 4: Immigrants' average productive human capital or skill level under the $q^{2}$ system is higher (equal) (smaller) than under the country-preference system if and only if educational quality in Country 1 relative to that of Country 2 is higher (equal) (smaller) than the degree of discrimination in favor of Country 1 relative to Country 2, i.e., $S_{q} \gtreqless$ $S_{p} \Leftrightarrow \beta \gtreqless \gamma$.

\section{Conclusion}

Up to 1967, Canada's immigration policy consisted of a country-preference system. The policy changed to the points system under the 1967 policy reform. The latter provides points for applicants' education level or quantity though not for educational quality. This paper considered the points and country-preference systems, as well as the $q^{2}$ system (that takes both the quantity and quality of education into account), focusing on the policies' impact on immigrants' average productive human capital or skill level $S_{x}$ (for policy $x$ ) as well as on the level of human capital in immigrants' source countries.

The paper showed, among others, that i) $S_{x}$ is greater under the $q^{2}$ system than under the points system $\left(S_{q}>S_{h}\right)$; ii) it is greater under the country-preference system than under the points system $\left(S_{p}>S_{h}\right)$; iii) with quality of education higher in Country 1 than in Country 2, whether $S_{x}$ is greater under the $q^{2}$ system or the country-preference system is ambiguous a priori: $S_{q}>(<) S_{p}$ if the quality of education in Country 1 relative to Country 2 is greater (smaller) than the degree of preference for Country 1 relative to Country 2; and iv) a switch from a points system to a $q^{2}$ system results in a net brain gain in Country 1 and a net brain drain in Country 2. 


\section{$\underline{\text { References }}$}

Aydemir, Abdurrahman, 2011, "Immigrant Selection and Short-Term Labor Market Outcomes by Visa Category,” Journal of Population Economics 24(2): 451-475.

Beine, Michel, Frédéric Docquier and Hillel Rapoport (2008), "Brain Drain and Human Capital Formation in Developing Countries: Winners and Losers.” Economic Journal 118: 631-52.

Boeri, Tito, Herbert Brücker, Frédéric Docquier and Hillel Rapoport. 2012. Brain Drain and Brain Gain: The Global Competition to Attract High-skilled Migrants. London: Oxford University Press

Clifton, Jonathan. 2010. "Fragmented Citizenship: Canadian Immigration Policy and Low-Skilled Portuguese Workers in Toronto.” Journal of Immigrant and Refugee Studies 8 (4): 409-30.

Commander, Simon, M. Kangasniemi and L. Alan Winters. 2004. "The Brain Drain: Curse or Boon? A Survey of the Literature,” in R.E. Baldwin and L.A. Winters (eds.). Challenges to Globalization: Analyzing the Economics, Chicago and London: University of Chicago Press.

Coulombe, Serge, Gilles Grenier and Serge Nadeau, 2012. "Human Capital Quality and the Immigrant Wage Gap," Working Papers 1212E, Department of Economics, University of Ottawa.

Docquier, Frédéric, Hillel Rapoport and Ayesegui Kayaoglu. 2011, “Managing Education Policy in High Brain-Drain Countries” Paper presented at the Fourth International Migration and Development Conference, Paris (June).

Green, Alan G. and David A. Green. 1995. "Canadian immigration policy: the effectiveness of the point system and other instruments." Canadian Journal of Economics 28 (4b): 1006 - 1041 (November).

Hinte, Holge, Ulf Rinne and Klaus F. Zimmermann. 2011. "A Points System for Demand-Oriented Control of Immigration to Germany.” IZA Research Report No. 35

Lucas, Robert E., Jr. 1988. “On the Mechanics of Economic Development.” Journal of Monetary Economics 22: 3 - 42 .

McHale, John and Keith Rogers. 2009. "Selecting Economic Immigrants: A Statistical Approach," Department of Economics Working Papers, No. 0145, National University of Ireland, Galway.

Mountford, Andrew. 1997. "Can a brain drain be good for growth in the source economy?” Journal of Development Economics 53: 287-303.

Phythian, David Walters and Paul Anisef. 2009. "Entry Class and the Early Employment Experience of Immigrants in Canada." Canadian Studies in Population, Vol. 36 (3-4): 363-382 (Fall/Winter) 
Schiff, Maurice. 2006. "Brain Gain: Claims about its Size and Impact on Welfare and Growth Have Been Greatly Exaggerated.” In C. Ozden and M. Schiff (eds.) International Migration, Remittances, and the Brain Drain. Palgrave MacMillan and World Bank.

Statistics Canada. 2001. "Immigrants' labour force rates, by immigration category." Ottawa.

2003. The rise in low-income rates among immigrants in Canada. Analytical Studies Branch research paper series (June), Ottawa

. 2007. "Chronic Low Income and Low-Income Dynamics Among Recent Immigrants” (January), Ottawa

Wall Street Journal, 2013 (August 31), "Canada Seeks Immigrants Who Fit Better. Ottawa Screens Applicants for English, French Fluency and "Adaptability" ”

\section{Appendix 1: Canada’s Points System}

The points system is used in Australia, Canada, Denmark, Hong Kong, New Zealand, Singapore, and in the UK (Tier 2) and points provided increase with the level of education.

In the case of Canada, the points obtained for various degrees and years of education are provided below (in bold). Figures in parenthesis are ratios of the minimum years of study needed, divided by the maximum number of years of study (assumed to be 20 years).

-PhD or Master's, AND at least 17 years (.85) of full-time study: 25

-Two or more Bachelor level degrees (.75) AND 15+ years of full-time study or three-year diploma, trade certificate or apprenticeship (DTA) AND 15+ years (.75) full-time study: 22

-A two-year university degree at the Bachelor's level AND 14+ years (.7) of full-time study or two-year DTA, AND 14+ years (.7) of full-time study: 20

-One-year university degree at the Bachelor's level AND 13+ years (.65) of full-time study or one-year DTA, AND 13+ years (.65) full-time study: 15

-A 1-year DTA, AND 12+ years (.6) of full-time study: 12

-Completed secondary school, assumed to require 12 years (.6) of full-time study: 5 -Less than completed secondary school (taken to be $<12$ years): $\mathbf{0}$

In order to obtain any points under Canada's points system, individuals must have a minimum, denoted by $h_{M}$, of 12 years of education (60\% of the maximum level of 20 years). Thus, $h_{M}=.6$ and the immigration probability is $p_{i}=0$ for $h_{i}<.6$ and $p_{i}\left(h_{i}\right)>$ $0, p_{i}^{\prime}>0$, for $h_{i} \geq h_{M}$.

\section{Appendix 2. Solution Under Discontinuity}

As mentioned in Section 2, Canada's points system requires a high-school degree, denoted by $h_{M}$, as a minimum level of education. This creates a discontinuity in the 
relationship between migration probability $p$ and human capital level $h$, with $p=0$, $h \epsilon\left[0, h_{M}\right)$ and $p=\pi h, h \epsilon\left[h_{M}, 1\right]$, where $h_{M}$ is the optimal level of human capital in the case where the quality of human capital is $q_{M}$.

Assume first that $q \epsilon\left[q_{M}, 1\right]$, implying $h^{*} \epsilon\left[h_{M}, 1\right]$. From equation (5), and deleting all subscripts, we have:

$e=\mu q h-\frac{h^{2}}{2}, \mu \equiv \alpha_{0}+\pi h\left(\alpha_{\mathrm{d}}-\alpha_{0}\right)$

Maximizing $e$, the optimal level of human capital is given by:

$h^{*}=\frac{\alpha_{0} q}{\varphi}, \varphi \equiv 1-2 \pi q\left(\alpha_{d}-\alpha_{0}\right), h \in\left[h_{M}, 1\right]$,

and

$e^{*}=\frac{\alpha_{0}^{2} q^{2}}{2 \varphi}$.

From (A2) and (A3), $h_{M}=\frac{\alpha_{0} q_{M}}{\varphi}$, and $e_{M}=\alpha_{0}^{2} q_{M}^{2} / 2 \varphi$.

In the case where $q \epsilon\left(0, q_{M}\right)$ and thus $h^{*} \epsilon\left(0, h_{M}\right)$, there are two possible solutions. A threshold quality (level or quantity) of human capital, denoted by $q_{0}\left(h_{0}\right)$, exists such that if $q\left(h^{*}\right)$ is below $q_{0}\left(h_{0}\right)$, migration does not take place, and if $q\left(h^{*}\right)$ is equal to or greater than $q_{0}\left(h_{0}\right)$, individuals raise their level of human capital to the level $h_{M}$, resulting in a positive probability of migrating and earn the higher destination-country wage rate. The solution for $q_{0}$ and $h_{0}$ is provided below.

If $q \epsilon\left(0, q_{0}\right)$, then $\pi=p=0$ and equation (A1) becomes $e=\alpha_{0} q h-\frac{h^{2}}{2}$, whose solution is $h_{1}^{*}=\alpha_{0} q$ and $e_{1}^{*}=\frac{\alpha_{0}^{2} q^{2}}{2}$. If $q \epsilon\left(q_{0}, q_{M}\right)$, individuals raise their human capital level to $h_{M}$ and $e_{2}^{*}=\left[\alpha_{0}+\pi h_{M}\left(\alpha_{\mathrm{d}}-\alpha_{0}\right)\right] q h_{M}-\frac{h_{M}^{2}}{2}=\mu q h_{M}-\frac{h_{M}^{2}}{2} \cdot{ }^{9}$

The level of human capital $h_{0}$ is determined by indifference between keeping the level of human capital at $h_{0}$ or raising it to $h_{M}$, i.e., by the equality $e_{1}^{*}=e_{2}^{*}$. From equation (A2), $h_{0}=\alpha_{0} q_{0}$ since $\pi=p=0$ for any $h<h_{M}$. Thus, we have $\frac{\alpha_{0}^{2} q_{0}^{2}}{2}=\mu q_{0} h_{M}-\frac{h_{M}^{2}}{2}$.

The solutions for $h_{0}$ and $q_{0}$ are:

$h_{0}=\alpha_{0} q_{0}, q_{0}=\frac{1}{\alpha_{0}^{2}}\left(\mu h_{M}-\sqrt{\left(\mu^{2}-\alpha_{0}^{2}\right) h_{M}^{2}}\right), \mu=\alpha_{0}+\pi h_{M}\left(\alpha_{\mathrm{d}}-\alpha_{0}\right)$.

\footnotetext{
${ }^{9}$ Note that since $q<q_{M}$, it follows that $e_{2}^{*}=e_{M}-\left[\alpha_{0}+\pi h_{M}\left(\alpha_{\mathrm{d}}-\alpha_{0}\right)\right]\left(q_{M}-q\right) h_{M}<e_{M}$.
} 